\title{
Impact of supported employment on service costs and income of people with mental health needs
}

Justine Schneider, University of Nottingham and Nottinghamshire Healthcare Trust, School of Sociology and Social Policy, Law and Social Sciences Building, University Park, Nottingham

Melanie Boyce, Institute of Health \& Social Care, Anglia Ruskin University, Chelmsford, Essex

Robyn Johnson, City University, London

Jenny Secker, South Essex Partnership NHS Trust and Anglia Ruskin University, Chelmsford, Essex

Jan Slade, School of Applied Social Sciences, Durham University, Durham

Bob Grove, The Sainsbury Centre for Mental Health, London, UK

Mike Floyd, City University, London

\begin{abstract}
Background: A 12-month study of UK supported employment providers found that 77 (54.6\%) of the participants in the study remained unemployed, $32(22.7 \%)$ got jobs and $32(22.7 \%)$ retained the jobs they held at the outset.

Aims: To explore the impact of moving into employment on service use, earnings, benefits and tax allowances claimed.

Methods: Service use and frequency were measured at baseline and 12 months. Comparisons paid particular attention to the differences between people entering work and those who remained unemployed. Costs were analysed from a government perspective (excluding earnings) and a societal perspective (excluding welfare benefits and taxes).

Results: People who entered work reduced their consumption of mental health services $(p<0.001)$. However, use of supported employment increased $(p=0.04)$, in contrast to falling use by people who remained unemployed $(p<0.001)$ and those who had been working for more than one year $(p=0.002)$. The increase in earnings for those entering work $(p=0.02)$ was not offset by a similar reduction in benefits.

Conclusion: This indicates that mental health services may make savings as a result of their clients engaging in paid work. It raises questions about the optimal nature and organization of employment support for this service user group.
\end{abstract}

Keywords: Employment, costs, benefits

\section{Background}

This paper investigates the costs and economic benefits associated with moving into and remaining in employment for people with severe mental health problems. Employment is increasingly accepted as an important outcome for secondary mental health care in England (National Social Inclusion Partnership, NIMHE, CSIP, 2006) and the proportion of service users in employment is a key target of the 2008-2013 Public Service Agreement, which underpins local planning. Practice demonstrates that paid employment is a realistic and achievable goal (Rinaldi \& Perkins, 2007). The sample studied here is of interest because it consists of fairly typical users of secondary mental health care.

The SESAMI (Social Inclusion through Employment Support for Adults with Mental Illness) study was a naturalistic investigation of the provision of supported employment for people with severe mental health problems in England in 2004-2006 (Boyce et al., 2008a; Johnson et al., 2009; SESAMI, 2007). Six agencies, among them public sector providers, private notfor-profit and voluntary organizations, participated. Three specialized in this service user group (Mental Health Matters, Richmond Fellowship Training and Employment, and South 
West London \& St George's Mental Health NHS Trust); the rest provided services for people with any kind of disability (JobCentre Plus, Remploy Interwork, and Shaw Trust). Although it was not a study of Individual Placement and Support as such (Bond, Drake, \& Becker, 2008) retrospective assessment of the services showed that all but one conformed to "fair" or "good" IPS implementation criteria (Boyce et al., 2008b).

A previous paper describes the impact of working on psychological well-being in this group, and reports variables predictive of going to work, notably time on agency caseload and attendance at a job centre (Schneider et al., 2008). This paper explores the impact of employment support on costs of services used, benefits claimed and earnings for three discrete groups of participants: those who were already working at the start of the study and remained in the same job $(n=32)$ those who obtained work just prior to the baseline interview or during the 12 month follow-up period $(n=32)$ and those who remained unemployed throughout the year $(n=78)$.

\section{Aim}

The analysis reported here was guided by three questions:

- Were there any demographic or diagnostic differences between people who got jobs and those who did not?

- How did going to work affect use of health and social care services?

- Did people come off state benefits when they went to work?

\section{Method}

\section{Sample identification}

Since all but one agency were independent of clinical mental health services, we had no reliable measure of severity of illness for most potential participants. We devised our own index based on the criteria for "severe and enduring mental illness" in the National Service Framework for Mental Health (Department of Health, 1999). Applying these severity criteria we screened out a high proportion of candidates for the study (SESAMI, 2007). This yielded 270 eligible candidates, of whom $59(22 \%)$ declined to participate or did not respond. This sample was further reduced to 174 because 29 were not receiving employment support and eight were in sheltered work. We followed up 145 (83\%) over 12 months.

Participants were interviewed face to face twice, 12 months apart, with a structured questionnaire. The interview included details of their work experience, state benefits and earnings as well as the Client Service Receipt Inventory (Beecham, 1995), which permitted the estimation of costs as described below.

\section{Estimating health and social care costs}

At baseline and follow up interviews we asked people to recall their use in the preceding three months of an exhaustive list of services. If they had used a service, they were asked to judge how much or for how long. With this information and published generic costs (Netten \& Curtis, 2005) we calculated average costs per week at baseline and a year later. The rationale behind this approach has been well established (Netten \& Beecham, 1993).

In the analysis of service costs, inputs are aggregated by providing agency to make inferences more robust. Thus, "mental health services" includes appointments with a psychiatrist, psychologist, community psychiatric nurse, attendance at a daycentre, counselling or therapeutic group work, together with inpatient mental health care, if applicable. "Primary care costs" include general medical practitioner, district nurse, community physiotherapist, dentist or optician. "Local authority costs" include day centres run by social services, home care and social work inputs. "Voluntary day centre costs" include day care run by not-for-profit agencies which are independent of the public sector. "Other secondary NHS costs" include hospital outpatient appointment and inpatient care for needs other than mental health. 


\section{Estimating agency input and costs}

The interviewees were clients of six employment support agencies operating at ten sites. Unlike the other costs reported here, employment-related input was calculated by the project grant administrator on the basis of data from each agency. These are therefore judged to be reliable measures of unit costs for this analysis. Given their different sources, supported employment costs are reported separately from other costs in this paper. For the same reason, comparisons between supported employment costs and non-supported employment costs, such as health social care, can be made only tentatively (Table I). The sample was not large enough to make meaningful comparisons between sites or agencies in terms of process, outcomes or clientele, rather, the participants were treated as a homogenous group of service users.

We multiplied duration of contact with the agency by the unit costs for that site to estimate supported employment input at each interview. Additional work related training costs calculated in a similar way were added to this amount. No adjustments were made for inflation or increases in unit costs over time. It should also be noted that half of the people included in these analyses were clients of London-based agencies, and services in the capital have recognizably higher costs for all health and social care services (Netten \& Curtis, 2005). Only $15 \%$ of the population of the UK lives in London, so the mean costs of SE and health and social care, as well as mean earnings, may be slightly inflated by this bias in the sample.

\begin{tabular}{|c|c|c|c|c|}
\hline Agency & $\mathrm{n}$ & Mean & SD & Median \\
\hline$A$ & 11 & 8.25 & 0.0 & 8.25 \\
\hline B & 19 & 25.25 & 0.0 & 25.25 \\
\hline C & 26 & 23.35 & 16.3 & 11.75 \\
\hline $\mathrm{D}$ & 34 & 26.26 & 11.3 & 20.75 \\
\hline$E$ & 13 & 16.25 & 0.0 & 16.25 \\
\hline $\mathrm{F}$ & 38 & 12.75 & 0.0 & 12.75 \\
\hline All & 141 & 19.62 & 10.9 & 15.75 \\
\hline
\end{tabular}

\section{Estimating earnings, benefits and allowances}

At the time of the study, all working age UK citizens not in employment were entitled to two main sources of financial support paid directly by the state. One source of support was contingent on their status as unemployed and/or disabled. This is called "welfare benefits" and the amount estimated here includes the total of Job Seeker's Allowance, Income Support, Statutory Sick Pay, Incapacity Benefit and Disabled Living Allowance received per week. A second source of support was relief from housing costs and taxes payable: Housing Benefit, Council Tax Benefit, Child Tax Credit, Working Tax Credit and Disabled Person's Tax Credit are included in this amount and called "allowances". Earnings per week after tax and National Insurance are also recorded, if applicable.

\section{Statistical transformations and analysis}

Descriptive statistics were used to profile the study participants. Mean costs at baseline and follow-up were estimated for the sample as a whole and for each group (remained unemployed, working less than one year, working more than one year). The aggregated costs data were characterized by a negative skew, so before using parametric tests we transformed raw costs by computing a logarithm to the base 10 , which resulted in a Normal distribution. It was necessary to add a small amount $(0.1)$ to all the zero costs in the dataset to permit this transformation without loss of cases (Bland, 2000). We also calculated the change in costs, benefits and earnings between baseline and follow-up, which was "normally" distributed. Paired and independent t-tests as appropriate were performed on the log transformed or "change" variables to compare three sub-groups: study participants who remained 
unemployed, those who were working up to 12 months by the end of the study, and those who at follow-up had more than one year's experience in the same job.

\section{Results}

Overall in the sample there were more men than women, the proportion of people from nonwhite ethnic minorities at $16.7 \%$ was comparable to much of urban England. The average age was 42.5 (standard deviation 9.9). The participants' history of psychiatric services involvement was fairly typical of a secondary care caseload (Table II, column 1) and although only one of the agencies was organizationally linked to a provider of mental health services nearly all the respondents had taken medication and/or consulted a mental health professional in the previous two years. Although at baseline none was actively experiencing symptoms which would prevent a person from working, two were excluded from the followup by their care co-ordinators because their mental health had deteriorated.

\section{Differences between people who got jobs and those who did not}

Those 32 people who went to work did so for a mean of 27 hours per week (standard deviation 14, median 27, mode 35 hours) data missing for two. There were no statistically significant differences between the people who went to work and those who did not (Table II) likely due to the small sample size, but three noteworthy variables approached significance. People who failed to obtain employment were twice as likely to have no qualifications as those who got work $(26.0 \% \vee 12.5 \% ; p=0.138)$. People who described their own mental health problems as "hearing voices", "hallucinations" or "schizophrenia" appeared twice as likely to remain unemployed as the rest $(28.4 \% \vee 12.5 \% ; p=0.133)$. People whose main mental health problem was depression tended to be more likely than others to be in work $(43.8 \% \vee 29.7 \% ; p=0.185)$.

\section{Changes in use of health \& social care services on entering work}

Tables III and IV offer a societal perspective on costs, omitting welfare benefits and taxes. Table III shows costs of services over the three months preceding the baseline (2005) and follow-up interview one year later (2006). The costs for employment support and training are given in full - total cost of inputs prior to baseline, and total costs between baseline and follow-up interviews.

Paired t-tests of the log-transformed costs data show that the mean reduction in aggregate mental health services and the mean increase in secondary care (non-mental health-related) were both statistically significant (Table III). In the case of secondary care, this difference could be traced to one outlier. The decrease in mental health services costs was sufficient to outweigh the slight increase in other secondary care, making an overall reduction in health and social care costs statistically significant $(p<0.001)$ for people entering work within one year.

Table IV presents the data from Table III by sub-group, showing differences in costs profiles. The people who had entered work within the past year were the only group whose total service related costs, other than supported employment, fell significantly $(p=0.002)$. This was due principally to the reduction in mental health service costs $(p<0.001)$. The group of people in longer-term employment also saw their mental health service use fall significantly over the course of the study, but the drop in their overall service use did not quite attain statistical significance $(p=0.067)$. By contrast, the costs of supported employment increased significantly for people who had worked for less than one year $(p=0.04)$ while they declined for those who remained unemployed $(p<0.001)$ as well as for those who had been working for longer $(p=0.002)$. Figure 1 profiles the differences in costs of mental health services and supported employment for each sub-group. There was no correlation between the time with the agencies and supported employment costs at either time point (baseline Pearson's

$r=-0.061$, follow-up $r=-0.065)$. Neither was there any correlation between time with the agencies and other costs aggregated (baseline $r=0.069$, follow-up $r=0.041$ ). Hours worked per week did correlate negatively with supported employment costs at baseline $(r=-0.0259$, 
$\mathrm{p}=0.085)$ and at follow up $(\mathrm{r}=-0.0265, \mathrm{p}=0.078)$ but these correlations did not attain statistical significance

\begin{tabular}{|c|c|c|c|}
\hline Column & 1 & 2 & 3 \\
\hline $\mathbf{N}$ & $\begin{array}{c}\text { All } \\
141 \\
\%\end{array}$ & $\begin{array}{c}\text { Remained } \\
\text { un-employed } \\
77 \\
\%\end{array}$ & $\begin{array}{c}\text { Working512 } \\
\text { months } \\
32 \\
\%\end{array}$ \\
\hline Female & 43.3 & 41.6 & 43.8 \\
\hline Non-white ethnic group & 16.7 & 21.3 & 9.7 \\
\hline $\begin{array}{l}\text { No formal qualifications above } \\
\text { GCSE level }\end{array}$ & 19.9 & 26.0 & 12.5 \\
\hline Self-attributed diagnosis: & & & \\
\hline Schizophrenia/hearing voices & 25.5 & 28.4 & 12.5 \\
\hline Anxiety & 24.1 & 27.0 & 28.1 \\
\hline Depression & 31.9 & 29.7 & 43.8 \\
\hline Bipolar disorder & 15.6 & 14.9 & 15.6 \\
\hline $\begin{array}{l}\text { Ever admitted to hospital for } \\
\text { mentalhealth problem (MHP) }\end{array}$ & 70.2 & 72.7 & 62.5 \\
\hline Admitted for MHP in past 2 years & 27.7 & 27.3 & 18.8 \\
\hline $\begin{array}{l}\text { Ever inpatient for more than } 6 \\
\text { months }\end{array}$ & 19.1 & 18.2 & 18.8 \\
\hline $\begin{array}{l}\text { Taking medication for MHP in } \\
\text { past } 2 \text { years }\end{array}$ & 96.1 & 94.8 & 100 \\
\hline $\begin{array}{l}\text { Consulted mental health } \\
\text { professional in past } 2 \text { years }\end{array}$ & 94.3 & 94.8 & 93.8 \\
\hline
\end{tabular}

\section{Effect of employment on benefits and earnings}

Focusing again on people who remained unemployed and those who moved into work during the study, Table $\mathrm{V}$ illustrates the change in earnings, benefits and state allowances. The adult national minimum wage at the time of the follow-up was $£ 5.05$, an increase of 20p over the previous year. At baseline for all those working the mean rate of pay per hour was $£ 6.45$ (standard deviation (SD) 5.33) and at follow-up the mean hourly rate was £6.33 (SD 6.00). These earnings data complement the societal perspective for economic analysis. By contrast, welfare benefits and allowances are of interest from a governmental perspective. Income from benefit entitlements went down across both groups, but (contrary to what one might expect) did not decline significantly more for people entering work $(p=0.72$, independent t-test). The mean entitlement to allowances such as help with housing, carers' allowance and child benefit did drop for those entering work, but this did not attain statistical significance $(p=0.16)$. Since some benefits (e.g., housing benefit) are income related, this may reflect the fact that the new workers include some low earners, and that more than half of them worked part-time. 
Figure 1. Costs by sub-group

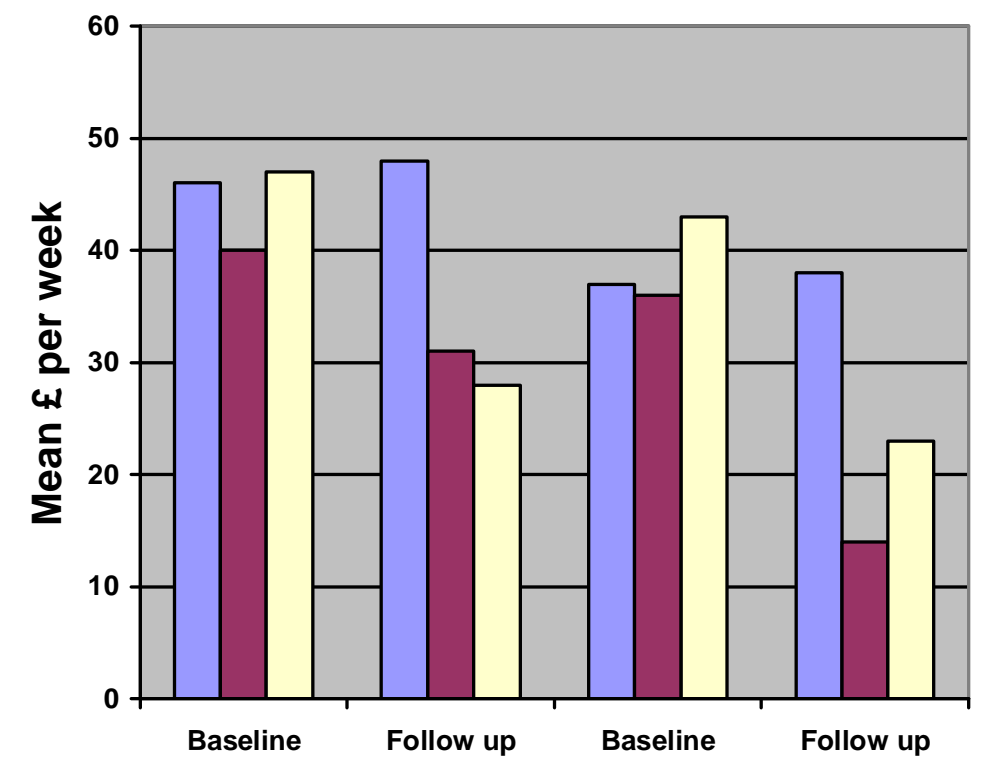

पUnemployed

$\square$ Working $<=12 \mathrm{~m}$

$\square$ Working >12m

All health \& social care input

Mental health services

\section{Discussion}

The features which characterize service users who succeed in gaining employment may guide interventions to help prepare individuals who wish to work, and to target support inputs more efficiently. Although these analyses are hampered by a relatively small sample size, they provide several important insights. The apparent difference in educational preparation identified here is relevant to the development of mental health services because it is amenable to intervention. A lack of basic skills is a severe disadvantage in the employment market. When this is combined with a chronic mental health problem, the prospects of employment are low. While people with some problems (schizophrenia/hearing voices) may have found it more difficult to obtain work than people with other problems (e.g., depression) this disadvantage is bound to be exacerbated by poor basic skills. Despite this, basic education is seldom a focus of mental health services (James, 2005) and the IPS approach (Bond, 2004) has explicitly downplayed training in the drive towards rapid job placement. Recently, however, educational achievement is becoming recognised as goal by mental health service users (Corrigan, Barr, Driscoll, \& Boyle, 2008; Nuechterlein et al., 2008). 


\begin{tabular}{|c|c|c|c|c|}
\hline$£$ per week & Mean & SD & $t$ (paired tests) & $\mathbf{p}$ \\
\hline Mental health services baseline & 38.45 & 62.96 & 4.812 & $<0.001$ \\
\hline follow-up & 29.60 & 55.29 & & \\
\hline Primary care: baseline & 2.58 & 3.88 & $<0.469$ & 0.639 \\
\hline follow-up & 2.83 & 4.11 & & \\
\hline Local authority: baseline & 4.07 & 15.06 & 0.657 & 0.512 \\
\hline follow-up & 2.83 & 9.68 & & \\
\hline Voluntary day care: baseline & 0.12 & 0.24 & 1.000 & 0.319 \\
\hline follow-up & 0.10 & 0.00 & & \\
\hline Other NHS secondary care: baseline & 0.36 & 1.64 & $<3.431$ & 0.001 \\
\hline follow-up & 4.74 & 32.90 & & \\
\hline All of the above: baseline & 45.26 & 68.01 & 3.770 & $<0.001$ \\
\hline follow-up & 39.78 & 67.27 & & \\
\hline SE inputs prior to baseline & 264.70 & 546.47 & 3.071 & 0.003 \\
\hline SE input baseline to follow-up & 100.71 & 341.01 & & \\
\hline
\end{tabular}




\begin{tabular}{|c|c|c|c|c|c|c|}
\hline \multirow{2}{*}{$\begin{array}{l}£ \text { mean per week } \\
\text { Mean } £ \text { per week }\end{array}$} & \multicolumn{2}{|c|}{$\begin{array}{c}\text { Remained } \\
\text { unemployed }\end{array}$} & \multicolumn{2}{|c|}{ Worked_12m } & \multicolumn{2}{|c|}{ Worked412m } \\
\hline & $\begin{array}{c}77 \\
\text { Mean } \\
\end{array}$ & SD & $\begin{array}{c}32 \\
\text { Mean } \\
\end{array}$ & SD & $\begin{array}{c}32 \\
\text { Mean }\end{array}$ & SD \\
\hline Mental health services: baseline & 37.14 & 60.69 & 36.71 & 45.76 & 43.35 & 82.12 \\
\hline follow-up & 38.63 & 65.74 & $14.30^{\star * \star}$ & 23.97 & $23.19^{* *}$ & 46.33 \\
\hline Primary care: baseline & 2.47 & 3.37 & 2.15 & 2.07 & 3.29 & 5.93 \\
\hline follow-up & 2.89 & 3.45 & 2.35 & 4.03 & 3.16 & 5.53 \\
\hline Local authority: baseline & 6.49 & 19.86 & 1.16 & 3.70 & 1.15 & 3.32 \\
\hline follow-up & 4.45 & 12.12 & 0.17 & 0.42 & 1.58 & 6.88 \\
\hline Voluntary day care: baseline & 0.10 & 0.00 & 0.19 & 0.50 & 0.10 & 0.00 \\
\hline follow-up & 0.10 & 0.00 & 0.10 & 0.00 & 0.10 & 0.00 \\
\hline $\begin{array}{l}\text { Other NHS secondary care } \\
\text { baseline }\end{array}$ & 0.50 & 2.10 & 0.11 & 0.03 & 0.30 & 1.11 \\
\hline follow-up & $2.71^{\star *}$ & 9.03 & $13.77^{*}$ & 67.61 & 0.62 & 2.31 \\
\hline All of the above: baseline & 46.37 & 70.06 & 40.00 & 45.51 & 47.86 & 82.14 \\
\hline $\begin{array}{l}\text { follow-up } \\
\text { Employment and training: }\end{array}$ & $\begin{array}{l}48.46 \\
\text { Remained } \\
\text { unemployed }\end{array}$ & 72.91 & Worked $<=12 \mathrm{~m}$ & 69.20 & Worked $>12 m$ & 46.92 \\
\hline $\begin{array}{l}\text { £ total } \\
\text { Prior to baseline } \\
\text { Baseline to follow-up }\end{array}$ & $\begin{array}{l}\text { Mean } \\
304.83 \\
72.29^{* \star *}\end{array}$ & $\begin{array}{c}\text { SD } \\
605.81 \\
266.98\end{array}$ & $\begin{array}{c}\text { Mean } \\
198.10 \\
238.66^{\star} \\
\end{array}$ & $\begin{array}{c}\text { SD } \\
288.59 \\
563.54\end{array}$ & $\begin{array}{c}\text { Mean } \\
234.72 \\
31.16^{\star *}\end{array}$ & $\begin{array}{c}\text { SD } \\
596.75 \\
78.83\end{array}$ \\
\hline
\end{tabular}

Key to aggregate costs:

Mental health services: CMHT, psych outpatients, psych inpatients, CPN, psychologist, NHS day hospital, counsellor, OT, NHS day/community centre, group work, Primary

health care: GP, Practice Nurse, physiotherapist, dentist, optician, Other secondary care: Other outpatients, other inpatients, Local Authority social services: Home care, Social worker, LA day care.

Asterisks indicate the level of significance of paired t-tests on each variable to investigate change between baseline and follow-up at the individual level: ${ }^{*}$ p50.05; ${ }^{* *}$ p50.01; ${ }^{* *} p 50.001$ 


\begin{tabular}{|l|l|l|l|c|c|}
\hline $\begin{array}{l}\text { Table V. Change in earnings, benefits and income for people entering work versus } \\
\text { those remaining unemployed (£ per week). }\end{array}$ & N & £ mean & t & p \\
\hline Variable & Group & & & & \\
\hline Change in earnings & Got work & 32 & 70.03 & 2.53 & 0.02 \\
& Remained unemployed & 77 & 11.09 & & \\
\hline Change in benefits & Got work & 32 & -17.34 & -3.55 & 0.72 \\
& Remained unemployed & 77 & -12.62 & & \\
\hline Change in other state & Got work & 32 & -7.19 & -1.41 & 0.16 \\
allowances & Remained unemployed & 77 & 0.56 & & \\
\hline
\end{tabular}

Although still tentative, a striking finding of this costs analysis is the reduction in use of mental health services by people who entered employment. This appears to be sustained in the longer term and is an important consideration for the implementation of IPS. Baseline use of services did not differ between people who started work and those who remained without jobs at follow-up. The median weekly cost of supported employment input was $£ 15.75$, and the cohort who started work reduced their consumption of mental health services by an average of $£ 23.93$ (range: $4.93-52.78, p=0.103$ ). A plausible interpretation is that the reduction in mental health service use is an effect and not a cause of getting a job, although the observational design of the study does not rule out the possibility that a third variable, such as cognitive impairment, might be driving both employment outcomes and service use reduction. Nonetheless, the results of this study suggest that mental health providers may save money if their service users get jobs.

From the perspective of costs to society, however, reduced service use is offset by an increase in employment support for the recently-employed, although this appears to decline after a person has been employed for more than one year. Figure 1 illustrates that people recently entering work on average received more inputs from the support agency than the unemployed at follow-up, but that people who have been in work for longer receive significantly less. Subject to confirmation in larger samples, this suggests that the need for support declines over time, making it possible that taxes paid by longer-term employees with mental health problems could offset the investment in employment support.

Does helping people into work reduce their reliance on state benefits? The evidence from this study is that, while earnings increased, benefits and allowances were not significantly affected. This is not particularly surprising considering that regulations limit the amount of earnings a person can have without losing their entitlement to claim such benefits. It is rational to optimise one's income from both benefits and earnings, especially if one is in an insecure job or if one may be susceptible to recurrent mental health problems. The findings from this analysis are consistent with the US study by Becker, Whitley, Bailey, and Drake (2007) which found that, even over 8-12 years, people preferred to work only part time to preserve their benefit entitlement. Reforms made to the system of state benefits implemented since the data were collected, such as the Employment and Support Allowance, should be monitored with a view to this finding.

\section{Conclusion}

This paper contributes to a sparse evidence base on the cost impact of supported employment (Perkins, Born, Raines, \& Galka, 2005; Schneider, 2003). It indicates that mental health services may stand to gain if their service users obtain work. In the longer term, the taxes paid on earnings by these people might even repay the investment in employment support. However these assertions remain to be demonstrated over time and in a representative sample of beneficiaries of employment support. 


\section{Acknowledgements and note on contributors}

Nicola Gardner, University of Durham, calculated the unit costs for the supported employment inputs. The study would not have been possible but for the funding of the European Social Fund Higher Education initiative, and the co-operation of the provider agencies and service users. Professor Eric Latimer made helpful suggestions about an earlier version of this paper. Professor Jenny Secker, Anglia Ruskin University and South Essex Trust, Bob Grove, The Sainsbury Centre for Mental Health and Professor Mike Floyd, City University, co-directed the study with the author. Jan Slade, Melanie Boyce and Robyn Johnson collected and costed the service use data analysed here.

\section{Declaration of interest:}

This paper is one output of a study funded by the European Social Fund, with contributions in kind from the following agencies providing supported employment: Department of Work and Pensions, Mental Health Matters, Remploy, Richmond Fellowship Training and Employment, Shaw Trust and South West London \& St George's Mental Health NHS Trust. All errors and omissions are the lead author's.

\section{References}

Becker, D., Whitley, R., Bailey, F.L., \& Drake, R.E. (2007). Long-term employment trajectories among participants with severe mental illness in supported employment. Psychiatric Services, 58, 922-928.

Beecham, J. (1995). Collecting and estimating costs. In M.R.J. Knapp (Ed.), The economic evaluation of mental health care (pp. 61-82). Aldershot: Arena.

Bland, M. (2000). An introduction to medical statistics, 3rd edn. Oxford: Oxford Medical Publications.

Bond, G. (2004). Supported employment: Evidence for an evidence-based practice. Journal of Psychiatric Rehabilitation, 27(4), 345-359.

Bond, G., Drake, R.E., \& Becker, D. (2008). An update on randomized controlled trials of evidence-based supported employment. Psychiatric Rehabilitation Journal, 31(4), 280-290.

Boyce, M., Secker, J., Johnson, R., Floyd, M., Grove, B., Schneider, J., \& Slade, J., (2008a). Mental health service users' experiences of returning to paid employment. Disability and Society, 23(1).

Boyce, M., Secker, J., Floyd, M., Grove, B., Johnson, R., Schneider, J., \& Slade, J. (2008b). Factors influencing the delivery of evidence-based Supported Employment in England Psychiatric Rehabilitation Journal, 31, 360-366.

Corrigan, P., Barr, L., Driscoll, H., \& Boyle, M. (2008). The educational goals of people with Psychiatric disabilities. Psychiatric Rehabilitation Journal, 32, 67-70.

Department of Health (1999). The National Service Framework for Mental Health. London: Department of Health.

James, K. (2005), Learning and skills for people experiencing mental health difficulties, Briefing sheet, NIACE, Leicester.

Johnson, R., Floyd, M., Pilling, D., Boyce, M., Grove, B., Schneider, J., Secker, J., \& Slade J. (2009). Services users' perceptions of the effective ingredients in supported employment. Journal of Mental Health, 18, 121-128.

National Social Inclusion Partnership, NIMHE, CSIP (2006). Commissioning guidance on vocational services for people with severe mental health problems. Gateway ref: 5659. London: Department of Health.

Netten, A., \& Beecham, J. (Eds.) (1993). Costing community care: Theory and practice. Aldershot: Ashgate.

Netten, A., \& Curtis, L. (2005). Unit costs of health and social care 2005. Personal Social Services Research Unit, University of Kent, Canterbury: PSSRU.

Nuechterlein, K., Subotnik, K., Turner, L., Venture, J., Becker, D., \& Drake, R.E. (2008). Individual placement and support for individuals with recent-onset schizophrenia: Integrating supported education and supported employment. Psychiatric Rehabilitation Journal, 31, 340-349. 
Perkins, D., Born, D., Raines, J., \& Galka, S. (2005). Program evaluation from an ecological perspective: Supported employment services for persons with serious psychiatric disabilities. Psychiatric Rehabilitation Journal, 28, 217-224.

Rinaldi, M., \& Perkins, R. (2007). Implementing evidence-based supported employment. Psychiatric Bulletin, 31, 244-249.

Schneider, J. (2003). Is supported employment cost effective? A review. International Journal of Psychosocial Rehabilitation, 7, 145-156.

Schneider, J. (2005). Employment support in the UK: Where are we now? In B. Grove, J. Secker, \& P. Seebohm (Eds.), New Thinking about Employment and Mental Health (pp. 37-49). Oxford: Radcliffe.

Schneider, J., Slade, J., Secker, J., Boyce, M., Johnson, R., Floyd, M., \& Grove, B. (2008). SESAMI study of employment support for people with severe mental health problems: 12 month outcomes. Health \& Social Care in the Community, 17(2), 151-158.

SESAMI (2007). Sesami Research Team and Practice Partnership. The SESAMI evaluation of employment support in the UK: Background and baseline data. Journal of Mental Health, 16(3), 375-387. 